\title{
Neurobrucellosis in a common bottlenose dolphin (Tursiops truncatus) stranded in the Canary Islands
}

\author{
Eva Sierra ${ }^{1}$, Antonio Fernández ${ }^{1 *}$ (D) Idaira Felipe-Jiménez ${ }^{1}$, Daniele Zucca', Gabriella Di Francesco², \\ Josué Díaz-Delgado ${ }^{1,3,4}$, Simona Sacchini ${ }^{1}$, Miguel A. Rivero ${ }^{1}$ and Manuel Arbelo ${ }^{1}$
}

\begin{abstract}
Background: Brucella spp. isolation is increasingly reported in cetaceans, although associated pathologies, including lesions of the musculoskeletal and nervous systems, are less frequently described. Concerning the nervous system, Brucella sp. infection causing meningitis, meningoencephalitis or meningoencephalomyelitis have been extensively reported in striped dolphins (Stenella coeruleoalba), and less frequently in other cetacean species.

Case presentation: A juvenile female common bottlenose dolphin (Tursiops truncatus) was found stranded alive in Lanzarote (Canary Islands, Spain) in 2005, but died shortly after. On physical examination, the dolphin showed a moderate body condition and was classified as code 2 (fresh dead) at the time of necropsy. The main gross findings were severe multiorgan parasitism, thickened and congested leptomeninges, and (sero)fibrino-suppurative and proliferative arthritis of the shoulder joint. Histopathological examination revealed the distinct features of a subacute systemic disease associated with Cetacean Morbillivirus (CeMV) infection. However, brain lesions diverged from those reported in systemic CeMV infection. This led to suspect that there was a coinfecting pathogen, based on the characteristics of the inflammatory response and the lesion distribution pattern in the central nervous system. Brucella sp. was detected in the brain tissue by PCR and Brucella antigen was demonstrated by immunohistochemistry in the brain and shoulder joint lesions.

Conclusions: The zoonotic potential of marine mammal strains of Brucella has been demonstrated both in natural and laboratory conditions. In this study, PCR detected Brucella sp. in the brain of a common bottlenose dolphin stranded in the Canary Islands; the dolphin was also co-infected with CeMV. This is the first detection of Brucella sp. infection in a stranded cetacean in this archipelago. Therefore, we stress the importance of taking adequate measures during the handling of these species to prevent the transmissions of the infection to humans.
\end{abstract}

Keywords: Brucella, Bottlenose dolphin, Canary Islands, Cetacean Morbillivirus, Neurobrucellosis

\section{Background}

Brucellosis is a zoonotic disease widely described in terrestrial mammals and in an increasing number of marine counterparts $[1,2]$. There have been many reported cases of Brucella spp. infection in marine mammals worldwide since its first simultaneous description (in cetaceans and pinnipeds) in 1994 [3, 4]. Based on their host specificity, two species of Brucella have been

\footnotetext{
* Correspondence: antonio.fernandez@ulpgc.es

${ }^{1}$ Division of Histology and Animal Pathology, Institute for Animal Health and Food Security (IUSA), Veterinary School, Universidad de Las Palmas de Gran Canaria, 35416 Arucas, Gran Canaria, Canary Islands, Spain

Full list of author information is available at the end of the article
}

described in marine mammals: $B$. ceti, with cetaceans as its preferred hosts, and B. pinnipedialis, which mainly infects pinnipeds [5]. Antibodies against Brucella spp. have been detected in a wide range of cetacean species (at least 53) [1, 2, 6-9], although Brucella-associated pathological findings have been reported less frequently. Specifically, the pathological findings described in common bottlenose dolphins (Tursiops truncatus) infected with Brucella spp. included: blubber abscesses [10], discospondylitis and vertebral osteomyelitis [11, 12], placentitis, and abortion [4, 13], and parasitic pneumonia and lung abscesses [14-16]. Brucella spp. infection

(c) The Author(s). 2019 Open Access This article is distributed under the terms of the Creative Commons Attribution 4.0 International License (http://creativecommons.org/licenses/by/4.0/), which permits unrestricted use, distribution, and reproduction in any medium, provided you give appropriate credit to the original author(s) and the source, provide a link to the Creative Commons license, and indicate if changes were made. The Creative Commons Public Domain Dedication waiver (http://creativecommons.org/publicdomain/zero/1.0/) applies to the data made available in this article, unless otherwise stated. 
associated with meningitis, meningoencephalitis or meningoencephalomyelitis has been widely reported in striped dolphins (Stenella coeruleoalba) [12, 17-24], and less frequently in other cetacean species: Atlantic whitesided dolphin (Lagenorynchus acutus) [25], short-beaked common dolphin (Delphinus delphis) [26], harbour porpoise (Phocoena phocoena) [27], long-finned pilot whale (Globicephala melas) [28], sperm whale (Physeter macrocephalus) [29], and common bottlenose dolphin [30, 31]. In addition, $B$. ceti has also been isolated from the brain of some species with no evidence of associated pathology $[18,32]$, which could be due to the virulence differences exhibited by some strains of $B$. ceti [33] and/or differences in species or individual susceptibilities. In this paper, we present a confirmed report of a central nervous system (CNS) pathology associated with Brucella sp. in a common bottlenose dolphin, previously reported to be infected with Cetacean Morbillivirus (CeMV) [34]. This is the first case of brucellosis in a cetacean species in the Canary Islands.

\section{Case presentation}

A juvenile female common bottlenose dolphin (laboratory identification number: I-225/05) was found stranded alive in Arrieta, Lanzarote (Canary Islands, Spain) in 2005, but died shortly after (Fig. 1). The total body length was $250 \mathrm{~cm}$, and a moderate body condition was estimated according to morphometric parameters [35]. A complete standardised necropsy was conducted within $6 \mathrm{~h}$ post-mortem. Samples were collected and stored by duplicate, fixed in $10 \%$ neutral buffered formalin for histology and immunohistochemistry (IHC) analyses and frozen at $-80{ }^{\circ} \mathrm{C}$ for molecular analysis. After fixation, tissue samples were trimmed and routinely processed. The tissues were then embedded in paraffin-wax, sectioned ( $5 \mu \mathrm{m}$-thick) and stained with hematoxylin and eosin (HE) for examination by light microscopy. Immunohistochemical analysis was performed on selected formalin-fixed, paraffin-embedded (FFPE) samples of brain, intestinal, lymphatic, pancreatic, pulmonary, renal, and splenic tissues, using a monoclonal antibody against Canine Distemper virus (CDV), as previously described [36]. Immunohistochemical detection of Brucella antigen was performed on brain and shoulder joint samples using a non-commercial monoclonal antibody produced at the Institute Zooprofilattico Sperimentale dell'Abruzzo e del Molise Giuseppe Caporale. The antibody reacts with $B$. melitensis biotype 1, 2 and $3 ; B$. melitensis Rev. 1 ; B. abortus biotype 2, 3 and 6; B. ceti; and B. pinnipedialis. Appropriate positive and negative IHC controls were included. The immunoreactivity observed in the positive control - a PCR-confirmed Brucella meningoencephalitis in a striped dolphin - consisted in macrophage-like cells harbouring bacterial antigen [Di Francesco G, Petrini A, D'Angelo AR, Di Renzo L, Luciani M, Di Febo $\mathrm{T}$, et al: Immunohistochemical investigations on neurobrucellosis-affected striped dolphins (Stenella coeruleoalba), unpublished]. Molecular detection of CeMV was performed by a 1-step reverse transcription conventional PCR of a 426-bp conserved region of the phosphoprotein $(\mathrm{P})$ gene [37]. A quantitative duplex-PCR amplifying a 150-bp fragment of the IS711 gene to detect Brucella at genus level and identify genotype ST27, was used for the Brucella PCR assay [38], which also included the shoulder joint (FFPE) sample. The assay also incorporated two negative controls (for extraction and amplification), and two amplification-positive controls: a Dolphin Morbillivirus detected in a Risso's dolphin (Grampus griseus) [39], for CeMV, and DNA from B. abortus (vaccine RB-51) [40], for Brucella spp. The obtained amplicons were purified using a commercial kit (Real Clean Spin kit 50 TestREAL), following the manufacturer's instructions, and subjected to Sanger DNA sequencing (Secugen S.L.,. Madrid, Spain). A BLAST search was conducted (www. ncbi.nlm.nih.gov/blast/Blast.cgi) to compare sequenced products with sequences described in GenBank for morbillivirus and Brucella spp.

Gross necropsy findings mainly comprised moderateto-severe parasitic infestation in several anatomic

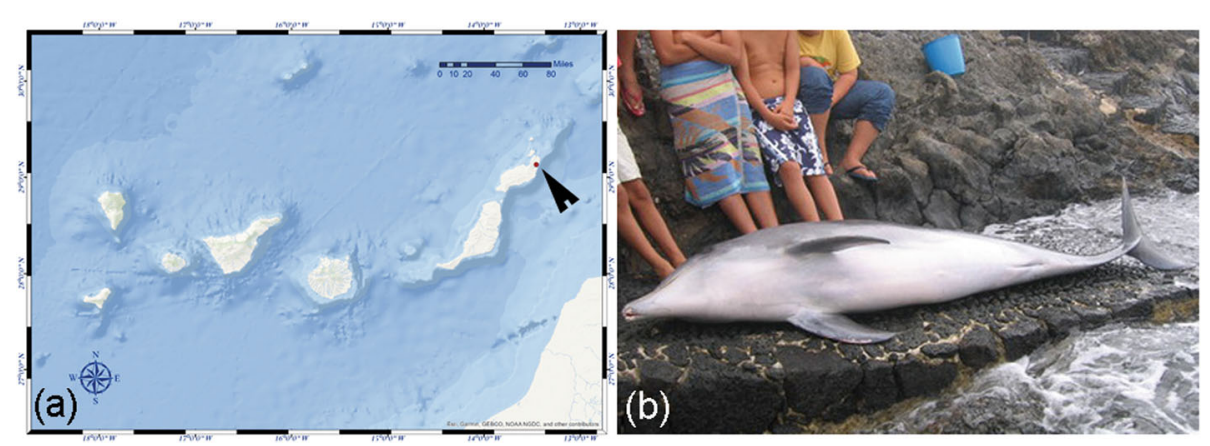

Fig. 1 a Map of the stranding location (red point, arrowhead) (QGIS). b. Ventro-lateral view of the stranded common bottlenose dolphin 
locations, including verminous pneumonia by larvae and adult nematodes (morphologically identified as Halocercus spp. and Stenurus spp.). Additionally, thickened and congested cerebral leptomeninges and bilateral (sero)fibrino-suppurative and proliferative arthritis of the shoulder joints were detected (Fig. 2). Microscopic lesions were those typically observed in sub-acute systemic disease associated with CeMV infection [41], affecting lungs, lymph nodes, spleen, intestines, kidneys, pancreas, adrenal glands, and brain [34]. Immunohistochemistry and PCR showed evidence of the virus in all the affected tissues [34]. Histopathologically, lesions in the CNS mainly consisted of non-suppurative meningoencephalitis, ventriculitis and myelitis. More specifically, these findings consisted in marked, multifocal, subacute-tochronic lymphohistiocytic meningoencephalitis with perivascular cuffing and gliosis in the cerebrum, cerebellum, spinal cord, and in the brainstem (pons). Additionally, the cerebrum and the brainstem (pons) presented granulomatous meningoencephalitis and ventriculitis with multinucleated giant cells and hemorrhage. The cerebrum also showed satellitosis, glial degeneration and necrosis, rarefaction/liquefactive necrosis, and vasculitis; the brainstem (pons) presented spongiosis and Wallerian degeneration; and the spinal cord showed evidence of glial nodules, white matter spongiosis and polyrradiculoneuritis. Finally, marked, multifocal, chronic lymphohistiocytic cranial neuritis, and meningitis and neurohypophisitis were present [42]. However - despite the severe non-suppurative meningitis (with more than 20 layers of histiocytic and lymphocytic cells), encephalomyelitis, and perineuritis in the CNS (Fig. 3) - immunopositivity against morbillivirus was only detected in some areas, with few lymphocytes, histiocytes, syncytial cells, and neurons, and some glial, and endothelial cells, showing positive immunostaining. Therefore, the nature of the inflammatory reaction, the lesion distribution pattern in the CNS, and the limited immunoreactivity, suggest a co-infection pathogen. The histopathological examination evidenced that the scapulohumeral synovium presented a severe, focally extensive, chronic necrosuppurative and granulomatous synovitis with fibroplasia, as well as rare bacteria and numerous multinucleated giant cells. These findings were consistent with previous descriptions of Brucella sp. infection in dolphins $[1,17,19,21,22,25,26]$. A 178-bp sequence length of the IS711 gene from the brain tissue was amplified (105-bp excluding primer length). This sequence showed a high similarity (99\%) when comparing identical partial regions of larger fragments of IS711 with Brucella sp. detected in cetaceans (GenBank acc. no. KJ482569; CP006896-CP006899; AB126349; AF242532AF242534). There was also a close similarity with $B$. pinnipedialis (GenBank acc. no. CP007742, CP007743, CP002078, and CP002079). However, Brucella strain ST27 delivered negative results. No amplification was obtained from the lung, spleen, and humeral joint samples. These preliminary results suggest that the subject of our study was infected by a marine Brucella strain. Nonetheless, further molecular characterisation will be necessary to better identify this strain.

Brucella sp. was detected by IHC in the CNS and in the shoulder joint. Immunostaining in the brain was observed in the cytoplasm of isolated mononuclear phagocytic cells in the meninges, inside meningeal vessels and in areas of cerebral cortex lying beneath the pia mater, which also presented a severe inflammation, mainly composed of macrophages and syncytia (with weak cytoplasmic immunoreaction) (Fig. 4). The antibody against morbillivirus showed the most intense immunopositivity in the same areas of the brain. Furthermore, immunostaining of the joint was located in the cytoplasm of isolated macrophages and multinucleated cells.

\section{Discussion and conclusions}

Involvement of the CNS in Brucella spp.-infected cetaceans has been reported more frequently in striped dolphins, suggesting that this species is much more vulnerable to neurobrucellosis than others [1,20]. Evidence of active Brucella spp. infection in the brain has

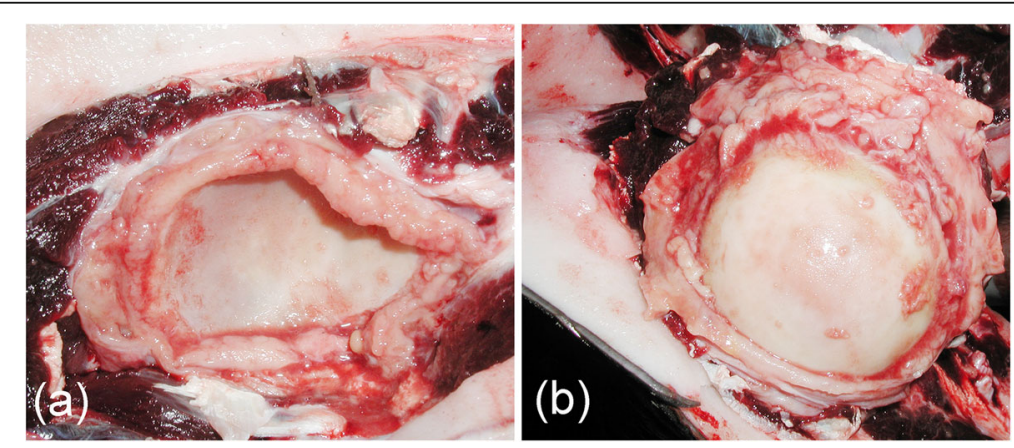

Fig. 2 (Sero)fibrino-suppurative and proliferative arthritis of the shoulder joint. a view of the scapular glenoid fossa. $\mathbf{b}$ view of the humeral head 


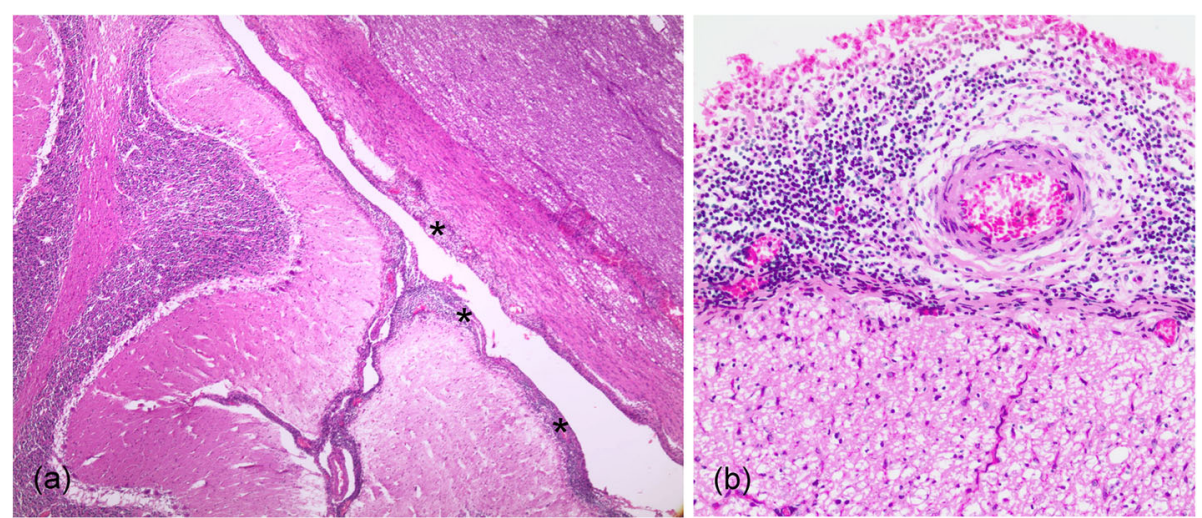

Fig. 3 Meningoencephalitis. a. Mononuclear infiltrates in the meninges surrounding the cerebellum (asterisks). HE. 4x. b. Several layers of mononuclear cells in the meninges of the medulla oblongata. HE. 20x

been less frequently reported in other cetacean species [25-29]. PCR-confirmed Brucella meningoencephalitis has also been described in the common bottlenose dolphin species [30, 31], with some cases of CeMV coinfections [43]. Cetacean Morbillivirus is the most pathogenic virus threatening dolphins and whales worldwide, and common bottlenose and striped dolphins are among the species that are the most susceptible to CeMV infection [36, 44-52]. Depending on the stage of the infection, four presentation forms of the disease have been recently proposed: acute-, subacute-systemic diseases, chronic systemic infection and chronic localised CeMV encephalitis. During the first two stages of the disease, typical lesions are present, although they can be largely obscured by those produced by secondary pathogens as a consequence of profound immunosuppression. Secondary opportunistic pathogens usually include Toxoplasma gondii, herpesviruses, bacteria (such as Photobacterium damselae) and fungi (such as Aspergillus fumigatus) [41]. Interestingly, few cases of Brucella and CeMV co-infection have been reported previously [29, $40,43,53]$. In those cases in which they were reported, more severe and extensive CNS inflammatory lesions were ascribed to Brucella sp. rather than to CeMV infection. Brain lesions related to Brucella sp. infection (neurobrucellosis) are typically located in the meninges and ependyma [1], while typical CeMV-associated brain lesions tend to involve the neuroparenchyma [41]. In our

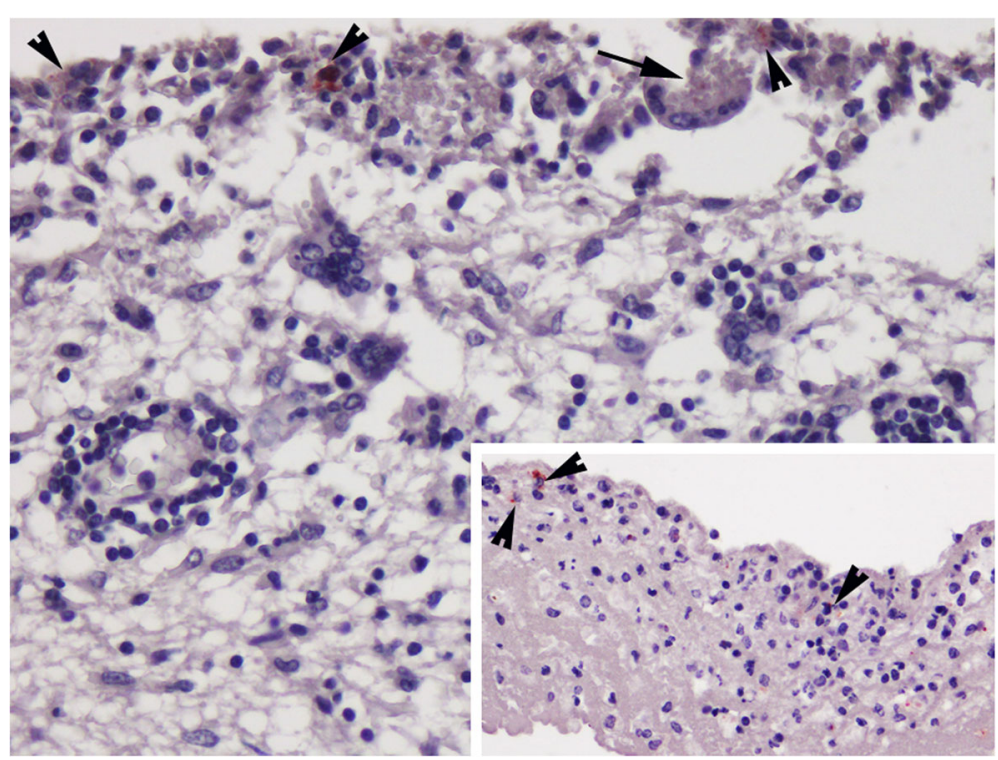

Fig. $4 \mathrm{Immunohistochemical} \mathrm{distribution} \mathrm{of} \mathrm{Brucella} \mathrm{antigen} \mathrm{in} \mathrm{the} \mathrm{central} \mathrm{nervous} \mathrm{system.} \mathrm{Immunolabeling} \mathrm{was} \mathrm{mainly} \mathrm{observed} \mathrm{in} \mathrm{the}$ cytoplasm of isolated mononuclear phagocytic cells (arrowheads) and syncytia (arrows) in the meninges and adjacent areas of cerebral cortex. IHC, HE counterstaining. 60x. Inset: immunopositivity in some monocytic cells (arrowheads) inside meningeal vessels. IHC, HE counterstaining. 40x 
case, systemic lesions were indicative of a sub-acute CeMV infection, while the chronicity and inflammatory features of brain lesions were more suggestive of Brucella sp. infection. The DNA Brucella amplicon amplified around cycle 30, which also correlates with the weak positivity by IHC in the brain (low bacterial load). Thus, since the inflammatory response pattern was largely associated with Brucella infection (neurobrucellosis), in our opinion, Brucella sp. was the main cause of meningoencephalitis in this dolphin. The low immunolabeling against Brucella could be explained by the chronicity of the infection (bacterial clearance by the inflammatory reaction) [19] or the relative insensitivity of Brucella IHC in areas with few bacteria [54], as previously suggested. However, CeMV also likely played a role, although those typical lesions were overlapped, masked, and/or non-evident. In contrast to previous reports, positive immunolabeling for morbillivirus and for Brucella by IHC were present in the CNS of the bottlenose dolphin from our study. Both positive immunolabeling also appeared in those areas where more macrophages (recognized cell target for Brucella and morbillivirus) and syncytia were present (Fig. 5). The latter finding could be interpreted as a reactivation of the Brucella infection in the brain (potentiated by the immune suppressive properties of CeMV), which could move morbillivirus-infected macrophages to the site, spreading the virus into the CNS. However, how or whether an interaction exists between these two CNS pathogens is unknown. Another question that arose was how this animal got infected. It has been suggested that
Brucella spp. infection can be transmitted horizontally (by sexual intercourse, maternal feeding, placental tissues or aborted fetuses) or vertically (from mother to the fetus). Other proposed transmission routes are through fish or helminth reservoirs [20, 21, 55, 56]. The estimated age of the subject and the course of the infection could evidence an in utero infection. This case adds a new record of Brucella sp. infection in the common bottlenose dolphin, a species in which reported cases of brucellosis are particularly scarce, despite the serological and molecular evidence of Brucella exposure reported both in free-ranging and under human care specimens worldwide $[6,9,10,13,38,57-59]$. This is the first detection of Brucella sp. in a cetacean stranded in the Canary Islands, a region with no reported cases of brucellosis for this taxon. The only evidence of brucellosis in the archipelago is a low prevalence of antibodies against Brucella sp. (1\%) described in camels $[60,61]$. The zoonotic potential of $B$. ceti, particularly the strain ST27 [62-64], has been previously discussed. Specifically, 4 human cases of acquired infection (3 natural and 1 laboratorial) by Brucella sp. from marine mammals, sharing the same genotype (ST27), based on multilocus sequence typing, have been reported [6467]. The presence of this strain has been detected in cetaceans from the Pacific waters $[1,4,38]$ and more recently in a common bottlenose dolphin from the northern Adriatic Sea found in Croatia [59]. Thus, special precautions should be taken when these marine mammal species are being handled (rescue, rehabilitation, necropsy and lab procedures).

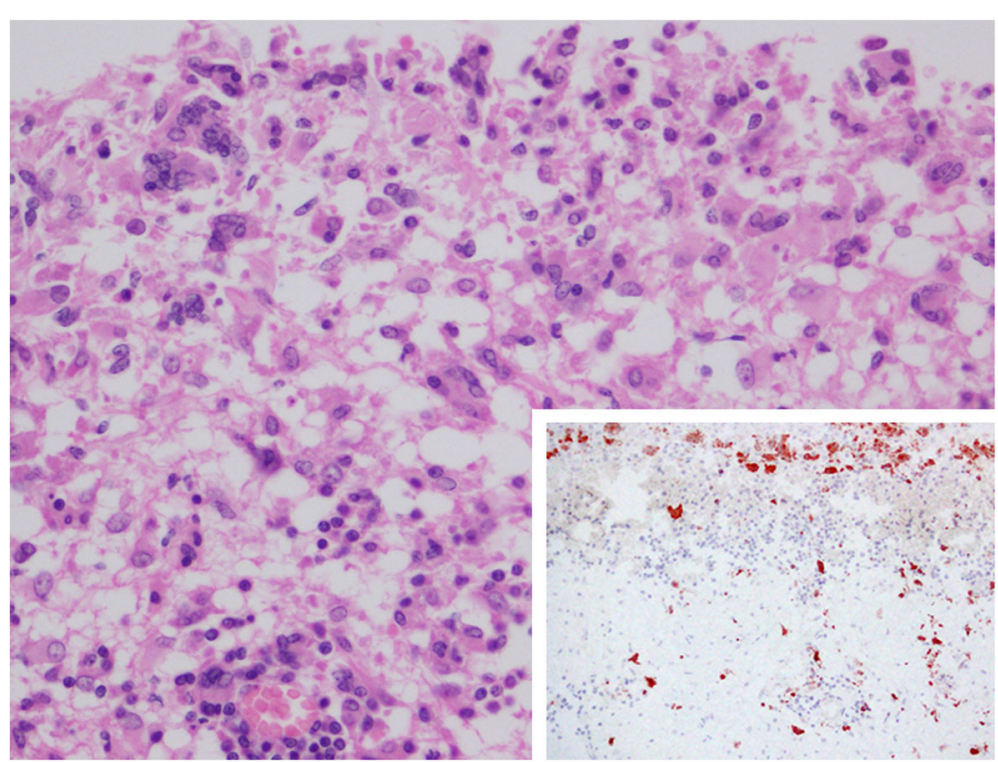

Fig. 5 Central nervous system, cerebral cortex. Lymphohistiocytic and granulomatous meningoencephalitis with multinucleated giant cells, perivascular cuffing, gliosis and hemorrhages. 60x. Inset: Immunolabeling against morbillivirus was predominantly within the cytoplasm of macrophages and multinucleated giant cells (syncytia) in the same areas. IHC, HE counterstaining. 20x 


\section{Abbreviations}

bp: Base pairs; CDV: Canine distemper virus; CeMV: Cetacean Morbillivirus; FFPE: Formalin-fixed, paraffin-embedded; HE: Hematoxylin and eosin; IHC: Immunohistochemistry; P gene: Phosphoprotein gene; PCR: Polymerase chain reaction

\section{Acknowledgments}

We thank the Canary Islands Regional Government and other members of the Canary Islands Cetacean Stranding Network, SECAC (Society for the Study of the Cetaceans in the Canarian Archipelago), and Canarias Conservación.

\section{Authors' contributions}

ES: this author redacted the work, contributed to the histological and molecular diagnosis of the case, and performed bioinformatics analyses. AF: this author contributes to the gross diagnosis of the case and guides to the first author during the redaction and publication process. IFJ: this author contributed to the molecular analysis of the case. DZ and GDF: these authors contributed to the immunohistochemical diagnosis of the case. JDD: this author contributed to the histological and etiological diagnosis of the case and guides to the first author during the redaction process. SS: this author contributed to the histological diagnosis of the case. MR: this author provided helpful discussions and critically reviewed the manuscript. MA: this author performed the necropsy, contributes to the gross diagnosis of the case and guides to the first author during the redaction process. All authors gave final approval of the version to be published.

\section{Funding}

This study was possible thanks to the funding by National Project CGL2015/ 71498P (Spain Government). The funding bodies were not involved in the either the design of the study or collection, analysis, and interpretation of data, nor were they involved in writing the manuscript.

\section{Availability of data and materials}

The datasets used and/or analysed during the current study are available from the corresponding author on reasonable request.

\section{Ethics approval and consent to participate}

The required permission for the management of stranded cetaceans anywhere within the Canarian archipelago was issued by the environmental department of the Canary Islands' Government. No experiments were performed on live animals because our work was based on dead stranded cetaceans, and the field studies did not involve endangered or protected species.

\section{Consent for publication}

Not applicable.

\section{Competing interests}

The authors declare that they have no competing interests.

\section{Author details}

${ }^{1}$ Division of Histology and Animal Pathology, Institute for Animal Health and Food Security (IUSA), Veterinary School, Universidad de Las Palmas de Gran Canaria, 35416 Arucas, Gran Canaria, Canary Islands, Spain. ${ }^{2}$ National and international Reference Laboratory for Brucellosis, Istituto Zooprofilattico Sperimentale Abruzzo e Molise, Teramo, Italy. ${ }^{3}$ Laboratory of Wildlife Comparative Pathology, School of Veterinary Medicine and Animal Science, University of São Paulo, São Paulo, SP, Brazil. ${ }^{4}$ Texas A\&M Veterinary Medical Diagnostic Laboratory (TVMDL), College Station, TX, USA.

Received: 2 October 2018 Accepted: 12 September 2019

Published online: 21 October 2019

\section{References}

1. Guzman-Verri C, Gonzalez-Barrientos R, Hernandez-Mora G, Morales JA Baquero-Calvo E, Chaves-Olarte E, et al. Brucella ceti and brucellosis in cetaceans. Front Cell Infect Microbiol. 2012;2(3):1-22.

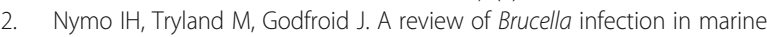
mammals, with special emphasis on Brucella pinnipedialis in the hooded seal (Cystophora cristata). Vet Res. 2011;42(93):1297-9716.
3. Ross HM, Foster G, Reid RJ, Jahans KL, MacMillan AP. Brucella species infection in sea-mammals. Vet Rec. 1994;134(14):359.

4. Ewalt DR, Payeur JB, Martin BM, Cummins DR, Miller WG. Characteristics of a Brucella species from a bottlenose dolphin (Tursiops truncatus). J Vet Diagn Investig. 1994;6(4):448-52.

5. Foster G, Osterman BS, Godfroid J, Jacques I, Cloeckaert A. Brucella ceti sp. nov. and Brucella pinnipedialis sp. nov. for Brucella strains with cetaceans and seals as their preferred hosts. Int J Syst Evol Microbiol. 2007:57(Pt 11): 2688-93.

6. Jepson PD, Brew S, MacMillan AP, Baker JR, Barnett J, Kirkwood JK, et al. Antibodies to Brucella in marine mammals around the coast of England and Wales. Vet Rec. 1997;141(20):513-5.

7. Nielsen O, Stewart RE, Nielsen K, Measures L, Duignan P. Serologic survey of Brucella spp. antibodies in some marine mammals of North America. J Wildl Dis. 2001:37(1):89-100.

8. Tachibana M, Watanabe K, Kim S, Omata Y, Murata K, Hammond T, et al. Antibodies to Brucella spp. in Pacific bottlenose dolphins from the Solomon Islands. J Wildl Dis. 2006;42(2):412-4.

9. Van Bressem MF, Van Waerebeek K, Raga JA, Godfroid J, Brew SD, MacMillan AP. Serological evidence of Brucella species infection in odontocetes from the South Pacific and the Mediterranean. Vet Rec. 2001;148(21):657-61.

10. Dawson CE, Perrett LL, Young EJ, Davison NJ, Monies RJ. Isolation of Brucella species from a bottlenosed dolphin (Tursiops truncatus). Vet Rec. 2006; 158(24):831-2

11. Goertz CE, Frasca S Jr, Bohach GA, Cowan DF, Buck JD, French RA, et al. Brucella sp. vertebral osteomyelitis with intercurrent fatal Staphylococcus aureus toxigenic enteritis in a bottlenose dolphin (Tursiops truncatus). J Vet Diagn Invest. 2011;23(4):845-51.

12. Isidoro-Ayza M, Ruiz-Villalobos N, Perez L, Guzman-Verri C, Munoz PM, Alegre $F$, et al. Brucella ceti infection in dolphins from the Western Mediterranean Sea. BMC Vet Res. 2014;10(206):014-0206.

13. Miller WG, Adams LG, Ficht TA, Cheville NF, Payeur JP, Harley DR, et al, Brucella-induced abortions and infection in bottlenose dolphins (Tursiops truncatus). J Zoo Wildl Med. 1999:30(1):100-10.

14. Cassle SE, Jensen ED, Smith CR, Meegan JM, Johnson SP, Lutmerding B, et al. Diagnosis and successful treatment of a lung abscess associated with Brucella species infection in a bottlenose dolphin (Tursiops truncatus). J Zoo Wildl Med. 2013:44(2):495-9.

15. Colegrove KM, Venn-Watson S, Litz J, Kinsel MJ, Terio KA, Fougeres E, et al. Fetal distress and in utero pneumonia in perinatal dolphins during the northern Gulf of Mexico unusual mortality event. Dis Aquat Org. 2016;119(1):1-16.

16. Davison NJ, Perrett LL, Law RJ, Dawson CE, Stubberfield EJ, Monies RJ, et al. Infection with Brucella ceti and high levels of polychlorinated biphenyls in bottlenose dolphins (Tursiops truncatus) stranded in south-West England. Vet Rec. 2011;169(1):15.

17. Davison NJ, Cranwell MP, Perrett LL, Dawson CE, Deaville R, Stubberfield EJ, et al. Meningoencephalitis associated with Brucella species in a live-stranded striped dolphin (Stenella coeruleoalba) in south-West England. Vet Rec. 2009; 165(3):86-9.

18. Foster G, MacMillan AP, Godfroid J, Howie F, Ross HM, Cloeckaert A, et al. A review of Brucella sp. infection of sea mammals with particular emphasis on isolates from Scotland. Vet Microbiol. 2002;90(1-4):563-80.

19. Gonzalez L, Patterson IA, Reid RJ, Foster G, Barberan M, Blasco JM, et al. Chronic meningoencephalitis associated with Brucella sp. infection in livestranded striped dolphins (Stenella coeruleoalba). J Comp Pathol. 2002: 126(2-3):147-52

20. Gonzalez-Barrientos R, Morales JA, Hernandez-Mora G, Barquero-Calvo E, Guzman-Verri C, Chaves-Olarte E, et al. Pathology of striped dolphins (Stenella coeruleoalba) infected with Brucella ceti. J Comp Pathol. 2010; 142(4):347-52.

21. Hernandez-Mora G, Gonzalez-Barrientos R, Morales JA, Chaves-Olarte E, Guzman-Verri C, Barquero-Calvo E, et al. Neurobrucellosis in stranded dolphins, Costa Rica. Emerg Infect Dis. 2008;14(9):1430-3.

22. Muñoz PM, Garcia-Castrillo C, Lopez-Garcia P, Gonzalez-Cueli JC, De Miguel MJ, Marin CM, et al. Isolation of Brucella species from a livestranded striped dolphin (Stenella coeruleoalba) in Spain. Vet Rec. 2006; 158(13):450-1.

23. Alba P, Terracciano G, Franco A, Lorenzetti S, Cocumelli C, Fichi G, et al. The presence of Brucella ceti ST26 in a striped dolphin (Stenella coeruleoalba) with meningoencephalitis from the Mediterranean Sea. Vet Microbiol. 2013; 164(1-2):158-63. 
24. Grattarola C, Giorda F, lulini B, Pintore MD, Pautasso A, Zoppi S, et al. Meningoencephalitis and Listeria monocytogenes, Toxoplasma gondii and Brucella spp. coinfection in a dolphin in Italy. Dis Aquat Org. 2016;118(2):169-74.

25. Dagleish MP, Barley J, Howie FE, Reid RJ, Herman J, Foster G. Isolation of Brucella species from a diseased atlanto-occipital joint of an Atlantic whitesided dolphin (Lagenorhynchus acutus). Vet Rec. 2007;160(25):876-8.

26. Davison NJ, Barnett JE, Perrett LL, Dawson CE, Perkins MW, Deaville RC, et al. Meningoencephalitis and arthritis associated with Brucella ceti in a short-beaked common dolphin (Delphinus delphis). Gangoso, L. 2013:49(3):632-6.

27. Jauniaux TP, Brenez C, Fretin D, Godfroid J, Haelters J, Jacques T, et al. Brucella ceti infection in harbor porpoise (Phocoena phocoena). Emerg Infect Dis. 2010;16(12):1966-8.

28. Davison NJ, Brownlow A, McGovern B, Dagleish MP, Perrett LL, Dale EJ, et al. First report of Brucella ceti-associated meningoencephalitis in a long-finned pilot whale Globicephala melas. Dis Aquat Org. 2015;116(3):237-41.

29. West KL, Levine G, Jacob J, Jensen B, Sanchez S, Colegrove K, et al. Coinfection and vertical transmission of Brucella and Morbillivirus in a neonatal sperm whale (Physeter macrocephalus) in Hawaii, USA. J Wildl Dis. 2015;51(1):227-32 PubMed PMID: 25390763. Epub 2014/11/13. eng.

30. Venn-Watson S, Colegrove KM, Litz J, Kinsel M, Terio K, Saliki J, et al. Adrenal Gland and Lung Lesions in Gulf of Mexico Common Bottlenose Dolphins (Tursiops truncatus) Found Dead following the Deepwater Horizon Oil Spill. PloS One. 2015;10(5):e0126538.

31. St Leger JA, S. R, A. M. Cetacea. In: Terio KA, D. M, St Leger J, editors. Pathology of Wildlife and Zoo Animals: Academic; 2018. p. 553-68.

32. Attademo FLN, Silva JCR, Luna FO, Ikeda J, Foppel EFC, Sousa GP, et al. Retrospective survey for pathogens in stranded marine mammals in northeastern Brazil: Brucella Spp. infection in a Clymene dolphin (Stenella Clymene). J Wildl Dis. 2018;54(1):151-5.

33. Maquart M, Le Fleche P, Foster G, Tryland M, Ramisse F, Djonne B, et al. MLVA-16 typing of 295 marine mammal Brucella isolates from different animal and geographic origins identifies 7 major groups within Brucella ceti and Brucella pinnipedialis. BMC Microbiol. 2009;9(145):1471-2180.

34. Sierra E, Zucca D, Arbelo M, Garcia-Alvarez N, Andrada M, Deniz S, et al. Fatal systemic morbillivirus infection in bottlenose dolphin, canary islands, Spain. Emerg Infect Dis. 2014;20(2):269-71.

35. Hart LB, Wells RS, Schwacke LH. Reference ranges for body condition in wild bottlenose dolphins Tursiops truncatus. Aquat Biol. 2013;18(6):63-8.

36. Fernandez A, Esperon F, Herraez $P$, de Los Monteros AE, Clavel C, Bernabe A, et al. Morbillivirus and pilot whale deaths, Mediterranean Sea. Emerg Infect Dis. 2008;14(5):792-4

37. Reidarson TH, McBain J, House C, King DP, Stott JL, Krafft A, et al. Morbillivirus infection in stranded common dolphins from the Pacific Ocean. J Wildl Dis. 1998;34(4):771-6.

38. Wu Q, McFee WE, Goldstein T, Tiller RV, Schwacke L. Real-time PCR assays for detection of Brucella spp. and the identification of genotype ST27 in bottlenose dolphins (Tursiops truncatus). J Microbiol Methods. 2014;100:99104 PubMed PMID: 24632518. Epub 2014/03/19. eng.

39. Sierra E, Fernandez A, Zucca D, Camara N, Felipe-Jimenez I, Suarez-Santana C, et al. Morbillivirus infection in Risso's dolphin Grampus griseus: a phylogenetic and pathological study of cases from the Canary Islands. Dis Aquat Org. 2018; 129(3):165-74 PubMed PMID: 30154276. Epub 2018/08/30. eng.

40. Sanchez-Sarmiento AM, Carvalho VL, Diaz-Delgado J, Ressio RA, Fernandes N, Guerra JM, et al. Molecular, serological, pathological, immunohistochemical and microbiological investigation of Brucella spp. in marine mammals of Brazil reveals new cetacean hosts. Transbound Emerg Dis. 2019;66(4):1674-92. PubMed PMID: 30980699. Epub 2019/04/14. eng.

41. Van Bressem MF, Duignan PJ, Banyard A, Barbieri M, Colegrove KM, De Guise $S$, et al. Cetacean morbillivirus: current knowledge and future directions. Viruses. 2014;6(12):5145-81.

42. Diaz-Delgado J, Groch KR, Sierra E, Sacchini S, Zucca D, QuesadaCanales $\mathrm{O}$, et al. Comparative histopathologic and viral immunohistochemical studies on CeMV infection among Western Mediterranean, northeast-central, and southwestern Atlantic cetaceans. PLoS One. 2019;14(3):e0213363 PubMed PMID: 30893365. Pubmed Central PMCID: PMC6426187. Epub 2019/03/21. eng.

43. NOAA. 2013-2015 Bottlenose dolphin Unusual Mortality Event in the MidAtlantic (Closed). https://www.fisheries.noaa.gov/national/marine-lifedistress/2013-2015-bottlenose-dolphin-unusual-mortality-event-mid-atlantic.
44. Duignan PJ, Geraci JR, Raga JA, Calzada N. Pathology of morbillivirus infection in striped dolphins (Stenella coeruleoalba) from Valencia and Murcia. Spain Can J Vet Res. 1992;56(3):242-8.

45. Domingo M, Vilafranca M, Visa J, Prats N, Trudgett A, Visser I. Evidence for chronic morbillivirus infection in the Mediterranean striped dolphin (Stenella coeruleoalba). Vet Microbiol. 1995;44(2-4):229-39.

46. Lipscomb TP, Kennedy S, Moffett D, Krafft A, Klaunberg BA, Lichy JH, et al. Morbilliviral epizootic in bottlenose dolphins of the Gulf of Mexico. J Vet Diagn Investig. 1996;8(3):283-90.

47. Taubenberger JK, Tsai M, Krafft AE, Lichy JH, Reid AH, Schulman FY, et al. Two morbilliviruses implicated in bottlenose dolphin epizootics. Emerg Infect Dis. 1996;2(3):213-6.

48. Raga JA, Banyard A, Domingo M, Corteyn M, Van Bressem MF, Fernandez M, et al. Dolphin morbillivirus epizootic resurgence, Mediterranean Sea. Emerg Infect Dis. 2008;14(3):471-3.

49. Rubio-Guerri C, Melero M, Esperon F, Belliere EN, Arbelo M, Crespo JL, et al. Unusual striped dolphin mass mortality episode related to cetacean morbillivirus in the Spanish Mediterranean Sea. BMC Vet Res. 2013;9(1):106.

50. Casalone C, Mazzariol S, Pautasso A, Di Guardo G, Di Nocera F, Lucifora G, et al. Cetacean strandings in Italy: an unusual mortality event along the Tyrrhenian Sea coast in 2013. Dis Aquat Org. 2014;109(1):81-6.

51. NOAA. What's Causing the Bottlenose Dolphin Deaths Along the MidAtlantic? https://www.neronoaagov/stories/2013/ bottlenoseDolphinAnnouncement.html. Accessed 12 Oct 2019.

52. Groch KR, Santos-Neto EB, Diaz-Delgado J, Ikeda JMP, Carvalho RR, Oliveira $\mathrm{RB}$, et al. Guiana dolphin unusual mortality event and link to cetacean Morbillivirus, Brazil. Emerg Infect Dis. 2018;24(7):1349-54 PubMed PMID: 29912687. Pubmed Central PMCID: PMC6038766. Epub 2018/06/19. eng.

53. Serrano L, Simeone CA, Colegrove KM, Duignan PJ, Goldstein T, Gulland FM. Cetacean Morbillivirus in Odontocetes stranded along the Central California coast, USA, 2000-15. J Wildl Dis. 2017;53(2):386-92.

54. Perez J, Quezada M, Lopez J, Casquet O, Sierra MA. Martin de las Mulas J. Immunohistochemical detection of Brucella abortus antigens in tissues from aborted bovine fetuses using a commercially available polyclonal antibody. J Vet Diagn Investig. 1998;10(1):17-21 PubMed PMID: 9526855. Epub 1998/ 04/04. eng.

55. Dawson CE, Perrett LL, Stubberfield EJ, Stack JA, Farrelly SS, Cooley WA, et al. Isolation and characterization of Brucella from the lungworms of a harbor porpoise (Phocoena phocoena). J Wildl Dis. 2008;44(2):237-46 PubMed PMID: 18436657. Epub 2008/04/26. eng.

56. Gelev I, Gelev E. A new species of fish-pathogenic bacterium antigenically related to classical Brucellae. Zentralbl Bakteriol Mikrobiol Hyg A. 1988;269(1): 1-6 PubMed PMID: 3176750. Epub 1988/07/01. eng.

57. Hernandez-Mora G, Manire CA, Gonzalez-Barrientos R, Barquero-Calvo E, Guzman-Verri C, Staggs L, et al. Serological diagnosis of Brucella infections in odontocetes. Clin Vaccine Immunol. 2009;16(6):906-15.

58. Alekseev AY, Rozanova EI, Ustinova EN, Tumanov YI, Kuvshinova IN, Shestopalov AM. The prevalence of antibodies to morbilliviruses, Brucella, and Toxoplasma in the Black Sea bottlenose dolphin Tursiops truncatus ponticus maintained in captivity. Russ J Mar Biol. 2007;33(6):425-8.

59. Cvetnic Z, Duvnjak S, Duras M, Gomercic T, Reil I, Zdelar-Tuk M, et al. Evidence of Brucella strain ST27 in bottlenose dolphin (Tursiops truncatus) in Europe. Vet Microbiol. 2016;196:93-7 PubMed PMID: 27939163. Epub 2016/ 12/13. eng.

60. Mentaberre G, Gutierrez C, Rodriguez NF, Joseph S, Gonzalez-Barrio D, Cabezon $\mathrm{O}$, et al. A transversal study on antibodies against selected pathogens in dromedary camels in the Canary Islands, Spain. Vet Microbiol. 2013;167(3-4):468-73.

61. Hernandez Cabrera M, Angel-Moreno A, Santana E, Bolanos M, Frances A, Martin-Sanchez MS, et al. Murine typhus with renal involvement in Canary Islands, Spain. Emerg Infect Dis. 2004;10(4):740-3.

62. Cloeckaert A, Bernardet N, Koylass MS, Whatmore AM, Zygmunt MS. Novel IS711 chromosomal location useful for identification of marine mammal Brucella genotype ST27, which IS associated with zoonotic infection. J Clin Microbiol. 2011:49(11):3954-9.

63. Whatmore AM. Current understanding of the genetic diversity of Brucella, an expanding genus of zoonotic pathogens. Infect Genet Evol. 2009;9(6): 1168-84.

64. Whatmore AM, Dawson CE, Groussaud P, Koylass MS, King AC, Shankster SJ, et al. Marine mammal Brucella genotype associated with zoonotic infection. Emerg Infect Dis. 2008;14(3):517-8. 
65. Brew SD, Perrett LL, Stack JA, MacMillan AP, Staunton NJ. Human exposure to Brucella recovered from a sea mammal. Vet Rec. 1999;144(17):483.

66. Sohn AH, Probert WS, Glaser CA, Gupta N, Bollen AW, Wong JD, et al. Human neurobrucellosis with intracerebral granuloma caused by a marine mammal Brucella spp. Emerg Infect Dis. 2003;9(4):485-8.

67. McDonald $W L$, Jamaludin $R$, Mackereth $G$, Hansen $M$, Humphrey $S$, Short $P$, et al. Characterization of a Brucella sp. strain as a marine-mammal type despite isolation from a patient with spinal osteomyelitis in New Zealand. J Clin Microbiol. 2006;44(12):4363-70.

\section{Publisher's Note}

Springer Nature remains neutral with regard to jurisdictional claims in published maps and institutional affiliations.

Ready to submit your research? Choose BMC and benefit from:

- fast, convenient online submission

- thorough peer review by experienced researchers in your field

- rapid publication on acceptance

- support for research data, including large and complex data types

- gold Open Access which fosters wider collaboration and increased citations

- maximum visibility for your research: over $100 \mathrm{M}$ website views per year

At $\mathrm{BMC}$, research is always in progress.

Learn more biomedcentral.com/submissions 